\title{
Specific Nutrient Intake Via Diet and/or Supplementation in Relation to Female Stress: A Cross-Sectional Study
}

\author{
Delia McCabe, ${ }^{1, *}$ Jana Bednarz, ${ }^{2}$ Craig Lockwood, ${ }^{1}$ and Timothy H. Barker ${ }^{1}$
}

\begin{abstract}
Background: Women are negatively impacted by psychological stress and despite the prolific use of dietary supplements to manage stress there is little evidence to support their use for such. This study examined the relationship between intake of specific nutrients through diet and/or dietary supplementation and level of perceived stress.

Method: In this cross-sectional study of adult Australian women $(n=74)$, perceived stress was measured using the Perceived Stress Scale, dietary intake was assessed using a validated Food Frequency Questionnaire, and supplement usage was recorded using a Supplement Use Questionnaire.

Results: Potentially substantive reductions in stress scores were associated with polyunsaturated fatty acid supplementation: $\alpha$-linolenic acid (mean difference $[\mathrm{MD}]=-3.34,95 \%$ confidence interval $[\mathrm{Cl}]=-7.97$ to 1.29), linoleic acid ( $M D=-4.08,95 \% C l=-8.97$ to 0.82 ), $\gamma$-linolenic acid ( $M D=-2.23,95 \% C l=-7.20$ to 2.74), and eicosapentaenoic acid (EPA)/docosahexaenoic acid (DHA) ( $M D=-4.05,95 \% \mathrm{Cl}=-8.07$ to -0.03$)$. There were negative correlations between intake of vitamin B6 and vitamin $C$ and stress $(\rho=-0.50$ and -0.35 , respectively). Compared with nonsupplementers, stress scores were on average 0.92 units lower among those supplementing with magnesium and vitamin B6 concurrently ( $95 \% \mathrm{Cl}=-3.88$ to 2.03). An increase in vitamin B6 through food was related to lower stress scores. For most nutrients, intake from food was positively associated with supplementation status.

Conclusion: There is some evidence to suggest potentially meaningful associations between intake of particular nutrients and stress, although Cls were wide and there were no statistically significant relationships observed. Further research is warranted to investigate any potential benefits more precisely using randomized controlled trials or large-scale observational studies.
\end{abstract}

Keywords: adaptation; dietary supplements; female; mood disorders/epidemiology; psychological; psychological/psychology; stress

\section{Background//ntroduction}

Psychological stress negatively impacts a significant number of women globally, with population level studies consistently reporting higher stress levels among women relative to men. ${ }^{1-3}$ Psychological stress is defined as "a particular relationship between the person and the environment [appraised] as taxing or exceeding their resources and endangering wellbeing" ( $p$. 19). ${ }^{4}$ Excessive or prolonged (chronic) stress impairs emotional, physical, cognitive, and social functioning and is a risk factor for the development of affective disorders. ${ }^{5}$ Examination of factors that are potentially

\footnotetext{
${ }^{1}$ The Joanna Briggs Institute, Faculty of Health and Medical Sciences, University of Adelaide, Adelaide, Australia.

${ }^{2}$ Adelaide Health Technology Assessment (AHTA), School of Public Health, The University of Adelaide, Adelaide, Australia.

*Address correspondence to: Delia McCabe, PhD, The Joanna Briggs Institute, Faculty of Health and Medical Sciences, University of Adelaide, 55 King William Road, North Adelaide, Adelaide, South Australia 5006, Australia, E-mail: delia.mccabe@adelaide.edu.au
}

(c) Delia McCabe et al. 2020; Published by Mary Ann Liebert, Inc. This Open Access article is distributed under the terms of the Creative Commons License (http://creativecommons.org/licenses/by/4.0), which permits unrestricted use, distribution, and reproduction in any medium, provided the original work is properly cited. 
protective against chronic stress, particularly among women where the burden of affective disorders is $50 \%$ higher relative to men, is warranted. ${ }^{6}$

Several factors may contribute to women's heightened experience of stress compared with men. These include psychosocial factors, such as persistent time constraints imposed on women by increasingly complex and competing societal roles and culture-specific stressors. ${ }^{7-10}$ Advances in the development of imaging technologies have also revealed gender differences in brain function and neurochemistry, including within the limbic system. ${ }^{11,12}$ Therefore, stress-related neurobiological mechanisms may differentially affect women and men. Such mechanisms include the development of a dysregulated stress response, whereby ongoing psychological stressors may chronically stimulate the synthesis and release specific hormones and cellular mediators aimed at mobilizing energy to address ongoing perceived threats. ${ }^{13-15}$ Chronic stress impacts several brain regions, including those involved in affective processing, such as the amygdala, hippocampus, and prefrontal cortex. ${ }^{16}$ Indeed, women are more susceptible to affective disorders than men $^{17}$ and also more likely to become depressed after stressful life events. ${ }^{18}$

There is biochemical evidence for the critical importance of specific nutrients for optimal central nervous system functioning, which includes energy metabolism, affective processing, cognitive functioning, hormone and neurotransmitter synthesis, and stress response regulation. ${ }^{19-23}$ Central to the body's stress response is the upregulation of stress hormones, such as cortisol, synthesis of which takes precedence over that of neurotransmitters regulating mood, appetite, and sleep, such as dopamine, serotonin, and melatonin. ${ }^{24-26}$

Nutrient requirements are increased under chronic stress, such that demand may exceed supply, and capacity for synthesis of neurotransmitters for affective regulation reduced. ${ }^{24,27,28}$ Furthermore, the body's return to homeostasis after a stressful period may be delayed or compromised by nutrient deficiencies. ${ }^{15}$ It is suggested that when under stress women's food preferences shift toward more calorie-dense and nutrientdeficient foods, increasing their susceptibility to nutritional deficiencies. ${ }^{29,30}$ This may impact neurotransmitter and hormone synthesis that require cofactors, including vitamins $B$ and $C$, magnesium, and zinc. ${ }^{20,21,31}$ In addition, polyunsaturated fatty acids (PUFAs) are critical for optimal neuronal functioning and energy metabolism. ${ }^{32,33}$
A cross-sectional study by Begdache et al. ${ }^{34}$ reported differences between men and women in the relationship between nutrient deficiency and mental wellbeing. A recent systematic review and meta-analysis found women reported significantly greater benefits from dietary interventions for symptoms of depression and anxiety compared with men ${ }^{35}$ and a year-long multivitamin and mineral (MVM) intervention was linked with mood improvement among women only. ${ }^{36}$ These results suggest that women may uniquely benefit from improved nutrient intake in the presence of stress, which may affect both nutritional choices and risk of nutrient deficiencies.

Although specific dietary patterns (DPs) have been linked with improvements in mental health, ${ }^{37-39}$ the impact of nutrient intake itself on perceived stress among women is presently under-examined. To date, just three studies examining the association between such nutrients and stress have included women in their study populations. In mixed-gender samples, Schlebusch et al. ${ }^{40}$ found significant reductions in stress levels associated with 30 days of supplementation with a B-vitamin complex, and Stough et al. ${ }^{41}$ reported a significant decrease in personal strain after supplementation with a high dose B vitamin complex for 12 weeks. In an all-female sample, Haskell et al. ${ }^{42}$ reported 9 weeks of MVM supplementation was associated with a reduction in selfreported stress levels.

Despite limited evidence, consumer expenditure on supplements claiming to be stress lowering, including $\mathrm{B}$ vitamins, vitamin $\mathrm{C}$, and magnesium, is expected to reach USD16.7 billion by $2025 .{ }^{43}$ In addition, use of vitamin and mineral supplements is higher among people with a history of anxiety and/or depression, among other health challenges. ${ }^{44}$ Kessler et al. ${ }^{45}$ reported that complementary or alternative therapies, including dietary supplement (DS) use, were estimated to be used by more than half of all the individuals diagnosed with anxiety or mood disorders in a population level study. Several large-scale surveys have found dietary supplementation to be more prevalent among women compared with men. ${ }^{46-48}$ Given the higher levels of stress reported by women, they may also be more likely to use DSs for stress reduction compared with men.

Nutrient sufficiency during periods of stress may provide a neurobiological defense against the development of affective disorders with recent evidence suggesting specific DPs may have a preventative effect on depression. ${ }^{38,49}$ Such research examined the role of nutrition in mental health by measuring DPs, where effects 
may be attributed to interactions between nutrients that occur with the consumption of whole foods. Nonetheless, the ubiquity and popularity of nutrient-specific products claiming stress reduction suggest supplementation with isolated nutrients is perceived effective by consumers. The lack of evidence to support the clinical use of supplements for the amelioration of stress led the researchers to examine relationships between specific nutrients consumed through diet and/or DSs and perceived stress levels in women.

\section{Methods}

Ethics

Full ethical disclosure can be found in the Ethical Standards Disclosure section.

\section{Study population}

This was a cross-sectional study, conducted online. A total of 87 women (21-70 years living in Queensland, Australia) were recruited, of which 74 completed the entire study ( $85 \%$ completion rate). Recruitment occurred through convenience sampling, through an online radio blog post, a city council newsletter, peers, and friends. Female residents of the Gold Coast were eligible to participate if they were 18 years or older at the time of recruitment, fluent in English, and could provide informed consent. Those who did not satisfy any one or more of these criteria were ineligible. Participants were required to complete three online surveys and could communicate with the researcher through a dedicated Facebook page or through email.

\section{Study design}

Participants were emailed URL links to three survey questionnaires through SurveyMonkey on the same day they supplied their email address ${ }^{50}$ (SurveyMonkey, Inc., San Mateo, CA). Data were collected over a 6-week period from August 12, 2016 to September 23, 2016.

\section{Perceived stress assessment}

Perceived stress levels were assessed using the selfreport Perceived Stress Scale (PSS-10) questionnaire, which is validated for use in nonclinical populations. ${ }^{51}$ PSS-10 scores were automatically calculated within the SurveyMonkey software.

\section{Dietary assessment}

An updated version of the Dietary Questionnaire for Epidemiological Studies (DQES version 3.2) was used to es- timate nutrient intake over the past 12 months by collecting food frequency information. ${ }^{52}$ The DQES, referred to as a Food Frequency Questionnaire (FFQ), was validated for assessing habitual dietary intake in the Australian population. ${ }^{53}$ Participant's usual intake of up to 152 foods and six alcoholic beverages were measured using 37 questions. Most food items used a 10-point scale and responses were guided by food portion images and beverage consumption guides. All frequency responses were converted to estimated daily nutrient equivalents using nutrient composition databases. ${ }^{54-56}$

\section{Supplement use assessment}

A self-administered Supplement Use Questionnaire (SUQ) was developed for this study by the first author (Supplementary Fig. S1). Existing questionnaires (Dietary Supplement Questionnaire [DSQ], ${ }^{57}$ Supplement Frequency Questionnaire $[\mathrm{SFQ}],{ }^{58}$ and Vitamins and Lifestyle [VITAL] $)^{59}$ were deemed inappropriate as they referred to specific supplements only and/or were insufficiently detailed with respect to usage, motivations for use, perceived effectiveness, and purchasing behavior. To construct a comprehensive list of the composition, form, dose, and usage instructions for readily available supplements, the first author visited a pharmacy and health store and examined the labels of $\sim 100$ DSs (including both MVMs and single-nutrient DSs). Questions were also developed to ascertain perceptions and behaviors associated with supplementation, including motivation for use and perception of effectiveness. Most questions were multiple choice. A screening question was included to establish respondent eligibility and instructions for completion were developed.

Pretesting of the questionnaire indicated face validity. A pilot test (feasibility study) was then administered using 10 purposively sampled women, including a dietician and a pharmacist, with feedback indicative of both face and content validity. Next, a specific face validity test was administered, using two groups of purposively sampled women, where one group had seen the SUQ before $(n=20)$ and the other had not $(n=20)$. There was high percentage of positive responses in both groups (95\% and 90\%, respectively) for questions assessing face validity.

The SUQ was adapted for use in SurveyMonkey. ${ }^{50}$ Information on usage and perceptions with respect to each supplement reported by each participant were obtained. 


\section{Statistical analysis}

Participant characteristics and questionnaire responses were summarized using means and standard deviations (SDs) for continuously measured variables, and frequencies and percentages for categorical items. Stress scores for supplementers and nonsupplementers were compared using the Mann-Whitney $U$ test. Ageadjusted associations between supplementation status for each nutrient and PSS scores were assessed using linear regression, and Spearman's rank correlations were used to test for associations between reported nutrient intakes and PSS scores. The relationship between nutrient intakes from food and supplementation status was examined using binary logistic regression. Where multiple outcomes were assessed, Sidak's adjustment was applied to control the Type I error rate. ${ }^{60}$ All analyses were performed using Stata (version 15). ${ }^{61}$ The level of statistical significance was set to 0.05 .

\section{Results}

Table 1 describes the demographic data of survey participants including their reported supplement use. Participants used between one ( $n=22$ participants) and five supplements ( $n=3$ participants) (Supplementary Tables S1-S5).

PSS scores ranged from 10 to 36 (Table 1). Mean PSS scores were slightly lower among women who used DSs $(\mathrm{M}=19.2, \mathrm{SD}=5.8)$ compared with women who did not use DSs $(M=21.4, S D=6.3)$. The Mann-Whitney $U$

\section{Table 1. Demographic Data, Number of Dietary Supplements Used, and Summary Statistics for Perceived Stress Scale Scores}

\begin{tabular}{lc}
\hline Participant characteristics & \\
\hline$N$ & 74 \\
Age in years (mean \pm SD) & $42.7 \pm 13.8$ \\
Supplement use & $58(78.4)$ \\
$\quad$ Yes, $n$ (\%) & \\
Total number of supplements used, $n$ (\%) & $22(29.7)$ \\
1 & $16(21.6)$ \\
2 & $10(13.5)$ \\
3 & $2(2.7)$ \\
4 & $3(4.1)$ \\
5 & $21(28.4)$ \\
N/A (No DS used or nutrients not of interest) & \\
Summary statistics for PSS scores & $19.66 \pm 5.90$ \\
Mean \pm SD & 19 \\
Median & 10 \\
Min & 36 \\
Max & \\
\hline
\end{tabular}

DS, dietary supplements; PSS, Perceived Stress Scale; SD, standard deviation. test indicated that differences in stress scores between groups were not statistically significant $(Z=1.20$, $p=0.231)$.

Effect of supplementation status for each nutrient on PSS scores: The age-adjusted point estimates and 95\% confidence intervals (CIs) indicate that potentially substantive reductions in PSS scores were associated with the use of specific nutrients including $\alpha$-linolenic acid, linoleic acid, $\gamma$-linolenic acid, and eicosapentaenoic acid (EPA)/docosahexaenoic acid (DHA) (Table 2). However, there is no consensus on what constitutes a clinically meaningful change in PSS scores. For most nutrients, average differences in PSS scores according to supplementation status were very small.

Nutrient intake from DSs and PSS scores: To assess whether there is any association between nutrient dosage and stress levels among regular supplementers, correlations between nutrient intake from supplements and PSS scores were carried out for those nutrients for which there were at least 10 supplementers among the sample with daily intake data available (Table 3). Results indicated positive correlations between EPA/DHA intake and PSS scores $(\rho=0.79)$, and weak negative correlations between vitamin $C$ intake and PSS scores $(\rho=-0.35)$ and between vitamin B6 intake and PSS scores $(\rho=-0.50)$. The Sidak correction was applied to account for multiple testing. The seemingly conflicting results for EPA/DHA supplementation compared with PUFA supplementation (Table 2) may be attributed by a number of factors, including uncertainty around the temporal relationship between perceived stress and supplementation.

Supplementation with specific nutrient combinations and PSS scores: The effect of concurrent magnesium and vitamin B6 supplementation on PSS scores was examined using linear regression. PSS scores were estimated to be 0.92 units lower on average compared with participants who did not supplement with either nutrient, but the difference was not statistically significant $(95 \% \mathrm{CI}=-3.88$ to $2.03 ; p=0.536)$.

Correlation between nutrient intake from food and PSS scores: There was limited evidence for any monotonic relationships between nutrient intake through food and PSS scores (Table 4).

Nutrient intake from food and PSS scores: A $10 \mathrm{mg}$ increase in vitamin B6 from food was associated with an average decrease of $\sim 3.5$ units in PSS score, although inspection of the $95 \%$ CI indicates a high level of uncertainty for this effect $(95 \% \mathrm{CI}=-28.43$ to 21.47). The point estimates and associated CIs for 
Table 2. Results of Linear Regression Models for Perceived Stress Scale Scores According to Supplementation Status for Nutrients of Interest

\begin{tabular}{|c|c|c|c|c|c|c|}
\hline \multirow[b]{2}{*}{ Nutrient } & \multirow{2}{*}{$\begin{array}{c}\text { Coefficient } \\
\text { (adjusted for age) }\end{array}$} & \multirow[b]{2}{*}{ Standard error } & \multicolumn{2}{|c|}{$95 \% \mathrm{Cl}$} & \multirow{2}{*}{$\begin{array}{l}\text { Unadjusted } \\
p \text {-value }\end{array}$} & \multirow{2}{*}{$\begin{array}{c}\text { Sidak-adjusted } \\
p \text {-value }\end{array}$} \\
\hline & & & Lower & Upper & & \\
\hline$\alpha$-linolenic acid* & -3.34 & 2.32 & -7.97 & 1.29 & 0.154 & 0.886 \\
\hline Linoleic acid & -4.08 & 2.45 & -8.97 & 0.82 & 0.101 & 0.775 \\
\hline$\gamma$-linolenic acid & -2.23 & 2.49 & -7.20 & 2.74 & 0.375 & 0.996 \\
\hline $\mathrm{EPA} / \mathrm{DHA}^{\mathrm{a}}$ & -4.05 & 2.02 & -8.07 & -0.03 & 0.048 & 0.522 \\
\hline Undefined $n-3$ & -1.56 & 2.19 & -5.92 & 2.80 & 0.478 & 0.997 \\
\hline Vitamin C & 0.05 & 1.37 & -2.68 & 2.77 & 0.973 & 0.998 \\
\hline Magnesium & -0.85 & 1.40 & -3.64 & 1.94 & 0.545 & 0.997 \\
\hline Zinc & -0.85 & 1.45 & -3.75 & 2.05 & 0.559 & 0.997 \\
\hline Thiamin (B1) & -1.27 & 1.41 & -4.07 & 1.54 & 0.372 & 0.996 \\
\hline Riboflavin/Niacin (B2/B3) & -1.14 & 1.42 & -3.97 & 1.69 & 0.426 & 0.996 \\
\hline Pantothenic acid (B5) & -0.63 & 1.51 & -3.65 & 2.38 & 0.678 & 0.997 \\
\hline Pyridoxine (B6) & -0.90 & 1.38 & -3.65 & 1.85 & 0.517 & 0.997 \\
\hline Folic Acid & -0.40 & 1.46 & -3.30 & 2.51 & 0.786 & 0.998 \\
\hline MTHFR $^{C}$ & -0.81 & 3.46 & -7.70 & 6.08 & 0.816 & 0.998 \\
\hline Cyanocobalamin (B12) & 0.24 & 1.38 & -2.51 & 3.00 & 0.860 & 0.998 \\
\hline
\end{tabular}

*The coefficient for $\alpha$-linolenic acid is -3.34 , which means that the PSS scores are 3.34 units lower, on average, for those who supplement with $\alpha$ linolenic acid compared with those who do not supplement with this nutrient. The $95 \% \mathrm{Cl}$ provides the range of plausible values for the "true" effect of $\alpha$-linolenic acid supplementation on PSS scores that are compatible given the observed data. We therefore cannot rule out that the "true" effect of $\alpha$ linolenic acid supplementation is as extreme as a 7.97 unit decrease in PSS scores and we cannot rule out that the "true" effect of such is a 1.29 unit increase in PSS scores (95\% Cl=-7.97 to 1.29) and the "true" effect may lie anywhere between these two values.

${ }^{a}$ Model estimates for EPA and DHA use are identical, because every person who was an EPA user was also a DHA user.

${ }^{b}$ Model estimates for riboflavin and niacin use are identical, because every person who was a riboflavin user was also a niacin user.

${ }^{\mathrm{C}}$ Activated folic acid supplement.

$\mathrm{Cl}$, confidence interval; DHA, docosahexaenoic acid; EPA, eicosapentaenoic acid; MTHFR, methylenetetrahydrofolate reductase.

the other nutrients of interest reveal relatively small effects of nutrient intake on PSS (Table 5).

Nutrient intake from food and DS status: With the exception of vitamin $\mathrm{C}$ and vitamin B6, on average, as intake of a nutrient from food increased so too did the odds of supplementing with that nutrient. However, after adjustment for multiple comparisons, there was little evidence against a null hypothesis of no effect of intake of food on supplementation status for any nutrient. The age-adjusted odds ratios describe the change in the odds of supplementing with a particular nutrient associated with an increase in intake of that nutrient from food (Table 6).

\section{Supplement use characteristics}

The most frequently reported supplements were PUFAs that accounted for $\sim 23 \%$ of the 107 DSs reported, followed by MVMs, which comprised $16 \%$ of reported supplements. Vitamin C, magnesium, and vitamin B12 accounted for $13.1 \%, 9.4 \%$, and $6.5 \%$ of supplements, respectively.

Table 3. Spearman's Rank Correlations for Daily Nutrient Intake Through Dietary Supplements and Perceived Stress Scale Scores for Selected Nutrients of Interest (for $n \geq 10$ )

\begin{tabular}{lccc}
\hline Nutrient & No. of observations & Rho $(\rho)$ & Unadjustedp-value \\
\hline$\alpha$-linolenic acid (mg/day) & 23 & 0.1157 & 0.5991 \\
Linoleic acid (mg/day) & 11 & 0.0780 & 0.8197 \\
EPA (mg/day) & 10 & 0.7903 & 0.0065 \\
DHA (mg/day) & 10 & 0.7903 & 0.0065 \\
Vitamin C (mg/day) & 33 & -0.3453 & 0.0491 \\
Magnesium (mg/day) & 29 & -0.1035 & 0.5930 \\
Zinc (mg/day) & 22 & -0.2444 & 0.2730 \\
Thiamin (B1) (mg/day) & 25 & -0.0296 & 0.8985 \\
Riboflavin (B2) (mg/day) & 23 & -0.3533 & 0.0982 \\
Niacin (B3) (mg/day) & 24 & -0.0931 & 0.0753 \\
Pantothenic acid (B5) (mg/day) & 20 & -0.1504 & 0.9947 \\
Pyridoxine (B6) (mg/day) & 29 & -0.4971 & 0.9220 \\
Cyanocobalamin (B12) (mg/day) & 27 & -0.1249 & 0.9947 \\
& & 0.6055 \\
\end{tabular}


Table 4. Spearman's Rank Correlations for Daily Intake of Selected Nutrients of Interest Via Food and Perceived Stress Scale Scores $(N=74)$

\begin{tabular}{lrc}
\hline Nutrient & Rho $(\rho)$ & $\begin{array}{c}\text { Sidak adjusted } \\
\boldsymbol{p} \text {-value }\end{array}$ \\
\hline Total $n$-3, mg/day & 0.0291 & 1.000 \\
Total $n-6, \mathrm{mg} /$ day & -0.0963 & 1.000 \\
Long chain $n$-3 & 0.0765 & 1.000 \\
Vitamin C, mg/day & -0.1891 & 0.925 \\
Magnesium, mg/day & -0.0749 & 1.000 \\
Zinc, mg/day & 0.1390 & 0.997 \\
Thiamin (B1) mg/day & -0.0206 & 1.000 \\
Riboflavin (B2) mg/day & -0.0542 & 1.000 \\
Niacin (B3) preformed, mg/day & 0.0222 & 1.000 \\
Niacin (Vitamin B3 + tryptophan & 0.0508 & 1.000 \\
$\quad$ derived), mg/day & & \\
Pantothenic acid (B5), mg/day & -0.0889 & 1.000 \\
Pyridoxine (B6), mg/day & -0.1335 & 0.998 \\
Biotin (B7), mg/day & -0.2020 & 0.889 \\
Folic acid, mg/day & 0.0519 & 1.000 \\
Folate, $\mu$ g/day & -0.0234 & 1.000 \\
Total folates, $\mu$ g/day & 0.0126 & 1.000 \\
Dietary folate, $\mu$ g/day ${ }^{a}$ & 0.0085 & 1.000 \\
Cobalamin (B12), mg/day & 0.1989 & 0.894 \\
\hline
\end{tabular}

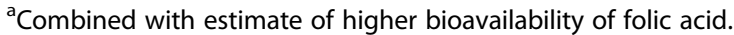

Most supplements $(65 / 107=61 \%)$ were reportedly consumed once daily. More than $60 \%$ of the supplements were reported to have been taken for at least 6 months duration and $38.7 \%$ had been taken for $>1$ year.

Fifty-five percent of reported supplements were perceived as being useful by their user, whereas the efficacy of $39 \%$ of supplements was perceived as "uncertain." The remaining $5 \%$ of supplements were perceived as not being useful. The most commonly reported motivations for DS use were to "increase energy" (applicable to $35 \%$ of supplements), "prevent disease" (applicable to $29 \%$ of supplements), and "reduce stress" (applicable to $27 \%$ of supplements) (Table 7 )

\section{Discussion \\ Summary of main findings in relation \\ to previous research}

In this study, mean PSS scores were generally lower among those who used DSs compared with those who did not and average PSS scores differed according to the number of DSs reportedly used. Among supplementers, a higher intake of vitamin B6 was associated with lower PSS scores, and similarly, increased intake of vitamin B6 from food was associated with a reduction in stress score. It was found that supplementing with magnesium and vitamin B6 in combination was linked with an approximate 1 unit reduction in PSS scores. Although these associations were not statistically significant after adjustment, the findings were broadly consistent with previous studies that have shown a B complex multivitamin reduced stress in women when administered continuously over a 30 -day ${ }^{40}$ or 90 -day period ${ }^{41}$ and existing literature suggested that magnesium may exert stresslowering effects. ${ }^{62-64}$ Many of the supplements accessed by participants contained magnesium, with more than half of all supplementers (31/58) obtaining magnesium through DSs. This may partly account for the lower stress levels observed among supplementers relative to nonsupplementers.

The effects of other B vitamins were inconclusive in this study. This may be owing to confounding by dose and duration of supplementation, which could not be

Table 5. Results of Linear Regression Models for Perceived Stress Scale Scores for Intakes of Selected Nutrients of Interest from Food

\begin{tabular}{|c|c|c|c|c|c|c|}
\hline \multirow[b]{2}{*}{ Nutrient } & \multirow{2}{*}{$\begin{array}{c}\text { Coefficient } \\
\text { (adjusted for age) }\end{array}$} & \multirow{2}{*}{$\begin{array}{l}\text { Standard } \\
\text { error }\end{array}$} & \multicolumn{2}{|c|}{$95 \% \mathrm{Cl}$} & \multirow{2}{*}{$\begin{array}{l}\text { Unadjusted } \\
p \text {-value }\end{array}$} & \multirow{2}{*}{$\begin{array}{c}\text { Sidak-adjusted } \\
p \text {-value }\end{array}$} \\
\hline & & & Lower & Upper & & \\
\hline$\alpha$-linolenic acid (per $1000 \mathrm{mg}$ ) & 0.298 & 1.187 & -2.070 & 2.666 & 0.803 & 1.000 \\
\hline Linoleic acid (per $1000 \mathrm{mg}$ ) & -0.072 & 0.138 & -0.346 & 0.202 & 0.602 & 1.000 \\
\hline EPA (per $100 \mathrm{mg})$ & 0.352 & 0.571 & -0.787 & 1.490 & 0.540 & 1.000 \\
\hline DHA (per 100 mg) & 0.172 & 0.291 & -0.409 & 0.753 & 0.558 & 1.000 \\
\hline Total $n-3$ (per $500 \mathrm{mg})$ & 0.243 & 0.482 & -0.719 & 1.205 & 0.616 & 1.000 \\
\hline Total $n-6$ (per $500 \mathrm{mg})$ & -0.034 & 0.069 & -0.172 & 0.103 & 0.619 & 1.000 \\
\hline Vitamin C (per 25 mg) & -0.273 & 0.230 & -0.732 & 0.187 & 0.241 & 0.988 \\
\hline Magnesium (per $10 \mathrm{mg}$ ) & -0.022 & 0.039 & -0.010 & 0.056 & 0.582 & 1.000 \\
\hline Zinc (per $10 \mathrm{mg}$ ) & 2.004 & 2.161 & -2.304 & 6.313 & 0.357 & 0.999 \\
\hline Thiamin (B1) (per $1 \mathrm{mg}$ ) & 0.051 & 0.830 & -1.602 & 1.705 & 0.951 & 1.000 \\
\hline Riboflavin (B2) (per $1 \mathrm{mg}$ ) & 0.202 & 0.762 & -1.319 & 1.722 & 0.792 & 1.000 \\
\hline Niacin (B3) (per $10 \mathrm{mg}$ ) & 0.500 & 0.844 & -1.183 & 2.182 & 0.556 & 1.000 \\
\hline Pantothenic acid (B5) (per $1 \mathrm{mg}$ ) & 0.355 & 0.562 & -0.765 & 1.478 & 0.529 & 1.000 \\
\hline Pyridoxine (B6) (per $10 \mathrm{mg}$ ) & -3.481 & 12.513 & -28.432 & 21.470 & 0.782 & 1.000 \\
\hline Biotin (B7) (per $1 \mathrm{mg}$ ) & -0.036 & 0.040 & -0.115 & 0.044 & 0.378 & 0.999 \\
\hline Total folates (per $100 \mu \mathrm{g}$ ) & 0.069 & 0.347 & -0.623 & 0.761 & 0.842 & 1.000 \\
\hline Cyanocobalamin (B12) (per $1 \mu \mathrm{g})$ & 0.646 & 0.390 & -0.132 & 1.423 & 0.102 & 0.839 \\
\hline
\end{tabular}


Table 6. Results of Logistic Regression Models for Supplementation Status for Selected Nutrients According to Recorded Intake from Food

\begin{tabular}{|c|c|c|c|c|c|c|}
\hline \multirow[b]{2}{*}{ Nutrient (obtained through food) } & \multirow{2}{*}{$\begin{array}{c}\text { Odds Ratio } \\
\text { (age-adjusted) }\end{array}$} & \multirow{2}{*}{$\begin{array}{l}\text { Standard } \\
\text { error }\end{array}$} & \multicolumn{2}{|c|}{$95 \% \mathrm{Cl}$} & \multirow{2}{*}{$\begin{array}{c}\text { Unadjusted } \\
p \text {-value }\end{array}$} & \multirow{2}{*}{$\begin{array}{c}\text { Sidak-adjusted } \\
p \text {-value }\end{array}$} \\
\hline & & & Lower & Upper & & \\
\hline$\alpha$-linolenic acid (per 1000 mg) & 1.310 & 0.866 & 0.359 & 4.789 & 0.683 & 0.943 \\
\hline Linoleic acid (per $1000 \mathrm{mg}$ ) & 1.105 & 0.090 & 0.943 & 1.296 & 0.217 & 0.851 \\
\hline EPA (per $100 \mathrm{mg}$ ) & 2.196 & 0.855 & 0.996 & 4.839 & 0.051 & 0.466 \\
\hline DHA (per 100 mg) & 1.368 & 0.231 & 0.983 & 1.904 & 0.063 & 0.511 \\
\hline Total $n-3$ (per $500 \mathrm{mg}$ ) & 1.130 & 0.275 & 0.701 & 1.821 & 0.616 & 0.943 \\
\hline Vitamin C (per 25 mg) & 0.932 & 0.077 & 0.793 & 1.095 & 0.391 & 0.918 \\
\hline Magnesium (per $10 \mathrm{mg}$ ) & 1.030 & 0.015 & 1.001 & 1.060 & 0.043 & 0.435 \\
\hline Zinc (per $1 \mathrm{mg}$ ) & 1.253 & 0.116 & 1.046 & 1.502 & 0.014 & 0.191 \\
\hline Thiamin (B1) (per $1 \mathrm{mg}$ ) & 1.319 & 0.384 & 0.746 & 2.335 & 0.341 & 0.918 \\
\hline Riboflavin (B2) (per 1 mg) & 1.553 & 0.432 & 0.900 & 2.680 & 0.114 & 0.664 \\
\hline Niacin (B3) (per $10 \mathrm{mg}$ ) & 1.699 & 0.532 & 0.920 & 3.139 & 0.090 & 0.611 \\
\hline Pantothenic acid (B5) (per $1 \mathrm{mg}$ ) & 1.094 & 0.230 & 0.724 & 1.653 & 0.671 & 0.943 \\
\hline Pyridoxine (B6) (per $1 \mathrm{mg}$ ) & 0.728 & 0.341 & 0.291 & 1.824 & 0.499 & 0.937 \\
\hline Total folates (per $100 \mu \mathrm{g}$ ) & 1.173 & 0.150 & 0.913 & 1.506 & 0.212 & 0.851 \\
\hline Cyanocobalamin (B12) (per $1 \mu \mathrm{g})^{\mathrm{a}}$ & 1.461 & 0.230 & 1.073 & 1.989 & 0.016 & 0.202 \\
\hline
\end{tabular}

${ }^{\mathrm{a}}$ For example, for every $1 \mu \mathrm{g}$ increase in vitamin B12 intake from food, the odds of supplementing with B12 increased.

completely controlled for, and low study power to detect small effects. Furthermore, this study investigated the effects of each individual $\mathrm{B}$ vitamin rather than a $\mathrm{B}$ vitamin complex, as the compositions of commercially available B vitamin complexes were highly variable. Effectiveness of supplementation may be contingent upon duration of supplementation, and any benefits may take time to have noticeable effects. Studies have reported reductions in self-reported stress associated

Table 7. Summary of Associated Dietary Supplement Use Variables

\begin{tabular}{lrr}
\hline Characteristic & Frequency & $\%$ \\
\hline Is the supplement helping achieve goals? $(n, \%)$ & 59 & \\
Yes & 6 & 55.1 \\
No & 42 & 5.6 \\
Unsure & & 39.3 \\
Reason for taking supplement, $(n, \%)$ & \\
Increase energy & 37 & 34.6 \\
Lose weight & 9 & 8.4 \\
Prevent disease & 31 & 29.0 \\
Reduce stress & 29 & 27.1 \\
Improve memory/concentration & 20 & 18.7 \\
Other & 61 & 57.0 \\
What prompted use of the supplement? (n, \%) & & \\
Doctor & 31 & 29.0 \\
Naturopath & 15 & 14.0 \\
Magazine & 13 & 12.2 \\
Newspaper & 1 & 0.9 \\
Ad & 0 & 0.0 \\
Other & 59 & 55.1 \\
Where is the supplement purchased? $(n, \%)$ & & \\
Health store & 38 & 35.5 \\
Supermarket & 38 & 4.4 \\
Naturopath & 25 & 7.5 \\
Online & 5 & 4.7 \\
Doctor & 8 & 34.6 \\
Other & 5 & \\
\hline
\end{tabular}

with continuous MVM supplementation among women over time periods ranging from 9 weeks $^{42}$ to 1 year. ${ }^{36}$ Reports of stress reduction after nutrient intervention may be because of the provision of a source of nutrients in short supply owing to appetite changes and increased metabolic demands that women experience when feeling stressed. ${ }^{29,30}$

Apart from being the most supplemented nutrient, the results indicated large potential benefits of some of the PUFA supplements with respect to stress levels. On average, stress levels were lower among those who supplemented with PUFAs compared with those who did not, with mean differences in PSS scores in the range of $\sim 2-4$ units across all four types of such supplements. However, for the subset of supplementers who reportedly used EPA/DHA, there was a positive association between EPA/DHA dosage and PSS scores. This may indicate that while stress levels tend to be lower overall among those who supplement with PUFAs relative to those who do not, usage among the EPA/DHA supplementers may increase or decrease according to their current level of perceived stress. However, these correlations are based on only a small subset of the sample $(n=10)$ and were not statistically significant.

Although the clinical importance of differences in PSS scores of these magnitudes are yet to be empirically determined, they may represent meaningful changes in perceived stress. This is consistent with existing research indicating PUFAs may have stress-lowering effects in both genders. ${ }^{65}$ Because of the cross-sectional study design, a causative relationship between these variables could not be established. 
With the exception of vitamins C and B6, the observed odds of supplementing with a particular nutrient increased as intake of that nutrient through food increased, although these effects were not statistically significant. This may suggest that supplementers were generally consuming higher amounts of the examined nutrients in their regular diets compared with nonsupplementers, implying that the former group is at lower risk of micronutrient deficiencies compared with the latter group. (Assessment of the nutritional adequacy of participants based on their reported food frequency intakes was beyond the scope of this study.) This result is broadly compatible with the 2013 National Health and Nutrition Examination Survey (NHANES), which found that DS use was greater among healthier respondents compared with less healthy respondents. ${ }^{57}$

Most DSs were reportedly consumed daily and used for at least 6 months. However, the efficacy of 39\% of the supplements consumed was perceived as "unsure" and $6 \%$ were perceived as not meeting the goals of the participant. There is no research that has examined why DSs would be consumed if their efficacy were in question.

\section{Agreement with existing literature}

Findings from this study can be compared with similar cross-sectional studies investigating dietary influences on mental health, although it should be noted that most of these studies examined food groups and DPs rather than individual nutrient intakes. Jacka et al. ${ }^{37}$ investigated the associations between diet ("Western" vs. "traditional") and depression and anxiety in a sample of Australian women. Less healthy, "Western" foods were associated with increased psychological symptoms compared with more traditional diets comprising minimally processed, whole foods, including grains, fish, and meat, which are assumed to be denser in nutrients, such as those examined in this study. Jacka et al. ${ }^{39}$ also investigated the relationship between habitual diet and mental health in elderly men and women. A healthy DP was found to be associated with reduced anxiety, but only in women. No association was found between magnesium intake through food and depression and anxiety in further studies by Jacka et al., ${ }^{66}$ and although there was some evidence for an effect of magnesium on stress in this study, this effect was relatively small in magnitude.

Previous research has indicated effects of nutrient intake on mental wellbeing may be moderated by gender. ${ }^{35}$ According to Begdache et al. ${ }^{34}$ the impact of nutrient density on mood regulation is more pronounced in women compared with men, and women may require more nutrients to support emotional wellbeing. The authors proposed that this finding may be attributable to differential effects of nutritional deficiencies on particular brain regions, such as the limbic system, between genders. ${ }^{34}$

\section{Strengths and limitations}

The cross-sectional nature of this study precludes making inferences about causative relationships between variables. The majority of the sample were supplement users, which may not reflect the true proportion of users in the general population. In addition, the small sample size limited the precision of results and power, such that only very large effects would have been detected at the $5 \%$ level. Inspection of the estimated effect sizes and CIs for the specific nutrients revealed that further research involving larger samples is warranted to investigate these relationships. ${ }^{67}$

Although the PSS is a validated tool, the population used for validation (college students) may not be representative of the population of interest in this project. ${ }^{51}$ Neither is the PSS a diagnostic or screening tool, so no normative data exist and this instrument does not discriminate between acute and chronic stress.

Nutrient intake was assessed using the DQES, a high-quality, comprehensive, and well-validated questionnaire. ${ }^{52}$ However, over- and underreporting are inherent in all FFQs. ${ }^{68}$ Multiple weeks of recorded dietary intake may have provided more accurate estimates of nutrient intake.

The SUQ was not formally tested for intra- or interrater reliability. It is likely that varying degrees of recall bias were associated with each instrument. ${ }^{69}$

Most DSs contained more than one nutrient, which complicated the analysis of the effects of dose-response and duration of specific-nutrient consumption on stress scores. Given the small sample size, the inclusion of adjustment factors to control for confounding in models was limited. Effects exerted by single nutrients may be moderated or confounded by other factors, including intakes of other nutrients. The effects of supplementation with specific nutrients may also differ depending on a person's preexisting nutritional status, such as whether a deficiency is present.

Some research suggests that the use of DSs is higher among those with a history of affective disorders. ${ }^{45}$ However, no data pertaining to previous or present mental health were collected in this study. The observed effect of supplementation on PSS score may 
therefore be confounded by mental health status, particularly in the presence of affective disorders. Specifically, a higher prevalence of mood disorders among supplementers versus nonsupplementers may be masking potential benefits of supplementation with respect to perceived stress. The PSS scores among participants in this study may therefore not accurately reflect the relationship between these scores and supplementation, as there may be some benefit from supplementation among those with affective disorders. An inability to compare PSS scores with mental health status is therefore a limitation.

Despite these limitations, including that this study did not explore DPs or chronic stress among women, it is the first study to examine the relationship between perceived stress and the intake of individual nutrients through diet and/or DSs among women. Furthermore, it supports a developing theory that stressed women may be unlikely to voluntarily participate in health research, which suggests innovative strategies are required to gather data on this demographic.

Where possible, strategies were implemented to ensure high-quality and efficient data collection. In this study we achieved a high completion rate $(85 \%)$ by using a range of recruitment and retention strategies to avoid attrition that may be relevant for other surveybased research. These strategies included engaging with local businesses and community groups who were willing to broadcast research invitations. Social media is increasingly being used to recruit participants for health research purposes and support communication toward survey completion. ${ }^{70}$ For this study, communication between participant and researcher was facilitated through a dedicated Facebook page. Furthermore, the development and use of the SUQ enabled information about supplement use to be readily collected without the need for structured interviews. The success of these strategies may help inform future health research.

\section{Conclusion}

This study sought to examine the effect of specific nutrients on stress in adult women. In general, evidence for an association between any single nutrient consumed through diet and/or DSs and perceived stress was inconclusive. However, substantive reductions in stress scores associated with supplementation with PUFAs, such as $\alpha$-linolenic acid, linoleic acid, $\gamma$-linolenic acid, and DHA/EPA, could not be ruled out. There was some evidence for a beneficial effect of vitamin B6 and vitamin $\mathrm{C}$ on stress, whereas little evidence was found to suggest supplementation with magnesium had any meaningful effect on perceived stress. Effects may have been confounded by factors including preexisting nutritional deficiency or adequacy, the presence of affective disorders, and overall diet composition.

The effect of nutritional intervention on stress is under-examined, despite chronic stress being an acknowledged antecedent of affective disorders. ${ }^{5}$ As similar nutrient and neurobiological mechanisms underpin mental health, further research is warranted to determine whether the effect of specific nutrient intake and/or DPs on stress is similar to their effects on depression. ${ }^{38,49,71}$

\section{Implications for future research}

Prospective cohort studies or randomized controlled trials, including both genders, will allow temporal and gender effects to be examined. Results from such studies may provide evidence to support either dietary changes and/or dietary supplementation to ameliorate the negative effects of stress. Dietary supplementation is a potential intervention for stress that is relatively safe, easy to administer, and generally well tolerated. However, until more evidence is available, women in this community who use DSs to ameliorate feelings of stress may experience benefits from including stress management strategies with a more established evidence base.

\section{Acknowledgments}

D.M. acknowledges the support received for postgraduate research through the provision of an Australian Government Research Training Program Scholarship from Adelaide University.

\section{Authorship Confirmation Statement}

Conception, design and acquisition of data: D.M.; drafting of article: D.M., J.B., C.L., and T.H.B.; final approval of article: C.L., T.H.B., and J.B.; statistical expertise: J.B.; contribution to the statistical expertise and interpretation of the data: D.M. and J.B.

\section{Ethical Standards Disclosure}

This study was conducted according to the guidelines laid down in the Declaration of Helsinki and all procedures involving research study participants were approved by the Office of Research Ethics, Compliance and Integrity, the University of Adelaide and written informed consent was obtained from all participants. The ethics registration and approval number was H-2016-090. 


\section{Author Disclosure Statement \\ No competing financial interests exist.}

\section{Funding Information}

This research received no specific grant from any funding agency, commercial or not-for-profit sectors.

\section{Supplementary Material \\ Supplementary Figure S1 \\ Supplementary Table S1 \\ Supplementary Table S2 \\ Supplementary Table S3 \\ Supplementary Table S4 \\ Supplementary Table S5}

\section{References}

1. American Psychological Association. Stress in America-The State of Our Nation, 2017. Available at: https://www.apa.org/news/press/releases/ stress/2017/state-nation.pdf Accessed February 15, 2020.

2. Statistics Canada. Perceived Life Stress, by age group, 2016-2017. Available at: https://www150.statcan.gc.ca/t1/tbl1/en/tv.action?pid= 1310009604 Accessed September 7, 2018.

3. Australian Psychological Society. Stress and wellbeing in Australia survey 2014. 2014. http://winneypsychology.com.au/wp-content/uploads/2015/ 08/2014-NPW-Key-findings-survey-stress-and-wellbeing.pdf Accessed March 22, 2017.

4. Lazarus RS, Folkman S. The stress concept in the life sciences. Stress, appraisal, and coping. New York: Springer, 1984:19.

5. Gold PW. The organization of the stress system and its dysregulation in depressive illness. Mol Psychiatry 2014;20:32-47.

6. Bangasser DA, Eck SR, Telenson AM, Salvatore M. Sex differences in stress regulation of arousal and cognition. Physiol Behav 2018;187:42-50.

7. Shrier DK. Career and workplace issues. In: Kornstein SG, Clayton AH, eds. Women's Mental Health-A comprehensive textbook. New York: The Guilford Press, 2002:527-541.

8. Boye K. Relatively different? How do gender differences in well-being depend on paid and unpaid work in Europe? Social Indicators Research 2009;93:509-525.

9. Lundberg U. Stress hormones in health and illness: The roles of work and gender. Psychoneuroendocrinology 2005;30:1017-1021.

10. World Health Organisation (WHO). The World Health Report 2001: Menta Health: New Understanding, New Hope, 2001; 169. Available at: www .who.int/whr/2001/en/whr01_en.pdf Accessed April 12, 2016.

11. Cosgrove KP, Mazure CM, Staley JK. Evolving knowledge of sex differences in brain structure, function, and chemistry. Biol Psychiatry 2007;62: 847-855.

12. McEwen BS, Milner TA. Understanding the broad influence of sex hormones and sex differences in the brain. J Neurosci Res 2017;95: 24-39.

13. Sapolsky RM. Stress and plasticity in the limbic system. Neurochem Res 2003;28:1735-1742.

14. Selye H. Stress and distress. Compr Ther 1975;1:9-13.

15. Murison R. The neurobiology of stress. In: Al'Absi M, Flaten MA, eds. The neuroscience of pain, stress, and emotion: Psychological and clinical implications. London: Elsevier, 2016:29-49.

16. Lupien S, Juster R-P, Raymond C, Marin M-F. The effects of chronic stress on the human brain: From neurotoxicity, to vulnerability, to opportunity. Front Neuroendocrinol 2018;49:91-105.

17. Bale TL. Stress sensitivity and the development of affective disorders. Horm Behav 2006;50:529-533.

18. Maciejewski PK, Prigerson HG, Mazure CM. Sex differences in eventrelated risk for major depression. Psychol Med 2001;31:593-604.

19. Rao TSS, Asha MR, Ramesh BN, Rao KSJ. Understanding nutrition, depression and mental illnesses. Indian J Psychiatry 2008;50:77-82.
20. Haller J. Vitamins and brain function. In: Lieberman HR, Kanarek RB, Chandan P, eds. Nutritional neuroscience. New Orleans, USA: Taylor \& Francis, 2005:207-233.

21. Long $S$, Benton D. Effects of vitamin and mineral supplementation on stress, mild psychiatric symptoms, and mood in nonclinical samples: A meta-analysis. Psychosom Med 2013;75:144-153.

22. Kennedy DO. B Vitamins and the brain: Mechanisms, dose and efficacyA review. Nutrients 2016;8:68.

23. Gómez-Pinilla F. Brain foods: The effects of nutrients on brain function. Nat Rev Neurosci 2008;9:568-578.

24. Ames BN. Low micronutrient intake may accelerate the degenerative diseases of aging through allocation of scarce micronutrients by triage. Proc Natl Acad Sci U S A 2006;103:17589-17594.

25. McCann JC, Ames BN. Vitamin K, an example of triage theory: Is micronutrient inadequacy linked to diseases of aging? Am J Clin Nutr 2009;90: 889-907.

26. Gibson GE, Blass JP. Nutrition and brain function. In: Siegel GJ, Agranoff BW, Albers RW, Fisher S, Uhler M, eds. Basic neurochemistry: Molecular, cellular and medical aspects. Philadelphia: Lippincott-Raven, 1999:691-709.

27. Bray TM, Levy MA. Dietary Zinc in Brain Development, Behaviour, and Neuropathology. In: Lieberman HR, Kanarek RB, Chandan P, eds. Nutritional Neuroscience. New Orleans, USA: Taylor \& Francis; 2005:275-288.

28. de Baaij JH, Hoenderop JG, Bindels RJ. Magnesium in man: Implications for health and disease. Physiol Rev 2015;95:1-46.

29. Mouchacca J, Abbott GR, Ball K. Associations between psychological stress, eating, physical activity, sedentary behaviours and body weight among women: A longitudinal study. BMC Public Health 2013;13:828.

30. Tomiyama AJ, Dallman MF, Epel ES. Comfort food is comforting to those most stressed: Evidence of the chronic stress response network in high stress women. Psychoneuroendocrinology 2011;36:1513-1519.

31. Harrison FE, Bowman GL, Polidori MC. Ascorbic acid and the brain: Rationale for the use against cognitive decline. Nutrients 2014;6:1752-1781.

32. Denis I, Potier B, Vancassel S, Heberden C, Lavialle M. Omega-3 fatty acids and brain resistance to ageing and stress: Body of evidence and possible mechanisms. Ageing Res Rev 2013;12:579-594.

33. Horrobin DF, Bennett CN. Phospholipid metabolism and the pathophys iology of psychiatric and neurological disorders. In: Peet M, Glen I, Horrobin DF, eds. Phospholipid spectrum disorders in psychiatry and neurology. United Kingdom: Marius Press, 2003:3-47.

34. Begdache L, Kianmehr H, Sabounchi N, Chaar M, Marhaba J. Principal component analysis identifies differential gender-specific dietary patterns that may be linked to mental distress in human adults. Nutr Neurosci 2020;23:295-308.

35. Firth J, Marx W, Dash S, et al. The effects of dietary improvement on symptoms of depression and anxiety: A meta-analysis of randomized controlled trials. Psychosom Med 2019;81:265-280.

36. Benton D, Haller J, Fordy J. Vitamin supplementation for 1 year improves mood. Neuropsychobiology 1995;32:98-105.

37. Jacka FN, Pasco JA, Mykletun A, et al. Association of western and traditional diets with depression and anxiety in women. Am J Psychiatry 2010; 167:305-311.

38. Lai JS, Hiles S, Bisquera A, Hure AJ, McEvoy M, Attia J. A systematic review and meta-analysis of dietary patterns and depression in communitydwelling adults. Am J Clin Nutr 2014;99:181-197.

39. Jacka FN, Mykletun A, Berk M, Bjelland I, Tell GS. The association between habitual diet quality and the common mental disorders in communitydwelling adults: The Hordaland Health study. Psychosom Med 2011;73: 483-490.

40. Schlebusch L, Bosch BA, Polglase G, Kleinschmidt I, Pillay BJ, Cassimjee $\mathrm{MH}$. A double-blind, placebo-controlled, double-centre study of the effects of an oral multivitamin-mineral combination on stress. S Afr Med J 2000;90:1216-1223.

41. Stough C, Scholey A, Lloyd J, Spong J, Myers S, Downey LA. The effect of 90 day administration of a high dose vitamin B-complex on work stress. Hum Psychopharmacol 2011;26:470-476.

42. Haskell CF, Robertson $B$, Jones $E$, et al. Effects of a multi-vitamin/mineral supplement on cognitive function and fatigue during extended multitasking. Hum Psychopharmacol 2010;25:448-461.

43. Goldstein Research: Global Stress Management Supplements Market Outlook 2017-2025. Market Report on Dietary Supplement Purchasing Trends, 2018. https://www.goldsteinresearch.com/report/stress-reliefsupplements-market-anxiety-management Accessed May 2, 2019. 
44. Marques-Vidal P, Pecoud A, Hayoz D, et al. Prevalence and characteristics of vitamin or dietary supplement users in Lausanne, Switzerland: the CoLaus study. Eur J Clin Nutr 2009;63:273-281.

45. Kessler RC, Soukup J, Davis RB, et al. The use of complementary and alternative therapies to treat anxiety and depression in the United States. Am J Psychiatry 2001;158:289-294.

46. Dickinson A, Blatman J, El-Dash N, Franco JC. Consumer usage and reasons for using dietary supplements: Report of a series of surveys. J Am Coll Nutr 2014;33:176-182.

47. Foote JA, Murphy SP, Wilkens LR, Hankin JH, Henderson BE, Kolonel LN. Factors associated with dietary supplement use among healthy adults of five ethnicities: The Multiethnic Cohort Study. Am J Epidemiol 2003;157: 888-897.

48. Radimer K, Bindewald B, Hughes J, Ervin B, Swanson C, Picciano MF. Dietary supplement use by US adults: Data from the National Health and Nutrition Examination Survey, 1999-2000. Am J Epidemiol 2004;160:339349.

49. Jacka FN, O'Neil A, Opie R, et al. A randomised controlled trial of dietary improvement for adults with major depression (the "SMILES" trial). BMC Med 2017;15:23.

50. Finley R, Finley C. SurveyMonkey, 1999. Available at: https://www .surveymonkey.com/ Accessed April 5, 2016.

51. Cohen S, Kamarck T, Mermelstein R. A global measure of perceived stress. J Health Soc Behav 1983;24:385-396.

52. Giles G, Ireland P. Dietary Questionnaire for Epidemiological Studies Version 2 (DQES v2), 2014. Available at: www.cancervic.org.au/ downloads/cec/FFQs/DQES_v3.2_Sample-Questionnaire.pdf Accessed January 22, 2017.

53. Hodge A, Patterson AJ, Brown WJ, Ireland P, Giles G. The anti cancer council of Victoria FFQ: Relative validity of nutrient intakes compared with weighed food records in young to middle-aged women in a study of iron supplementation. Aust N Z J Public Health 2000;24:576-583.

54. Bassett JK, English DR, Fahey MT, et al. Validity and calibration of the FFQ used in the Melbourne Collaborative Cohort Study. Public Health Nutr 2016;19:2357-2368.

55. Food Standards - Australia New Zealand: Australian Food Compostion Database (previously called NUTTAB), 2010. Available at: www .foodstandards.gov.au/science/monitoringnutrients/afcd/Pages/default .aspx Accessed August 3, 2017.

56. Food Standards-Australia New Zealand: Australian Food, Supplement and Nutrient Database (AUSNUT), 2007. Available at: https://www .foodstandards.gov.au/science/monitoringnutrients/ausnut/documents/ AUSNUT 2007- Explanatory Notes.pdf.

57. Bailey RL, Gahche JJ, Miller PE, Thomas PR, Dwyer JT. Why US adults use dietary supplements. JAMA Intern Med 2013;173:355-361.

58. Yonemori KM, Morimoto Y, Wilkens LR, Murphy SP. Development of a supplement composition database for the SURE Study. J Food Compost Anal 2009;22(S1):S83-S87.

59. Satia-Abouta J, Patterson RE, King IB, et al. Reliability and validity of selfreport of vitamin and mineral supplement use in the vitamins and lifestyle study. Am J Epidemiol 2003;157:944-954.

60. Šidák Z. Rectangular confidence regions for the means of multivariate normal distributions. J Am Stat Assoc 1967;62:626-633.

61. StataCorp: Stata Statistical Software: Release 15. College Station, TX: StataCorp LLC, 2017. Available at: https://www.stata.com/ Accessed January 22, 2019.

62. McCabe D, Lisy K, Lockwood C, Colbeck M. The impact of essential fatty acid, B vitamins, vitamin $C$, magnesium and zinc supplementation on stress levels in women: A systematic review. JBI Database System Rev Implement Rep 2017;15:402-453.

63. Jung K, Ock S, Chung J, Song C. Associations of serum Ca and Mg levels with mental health in adult women without psychiatric disorders. Biol Trace Elem Res 2010;133:153-161.

64. Pouteau E, Kabir-Ahmadi M, Noah L, et al. Superiority of magnesium and vitamin B6 over magnesium alone on severe stress in healthy adults with low magnesemia: A randomized, single-blind clinical trial. PLoS One 2018; 13:e0208454.

65. Carter JR, Schwartz CE, Yang H, Joyner MJ. Fish oil and neurovascular reactivity to mental stress in humans. Am J Physiol Regul Integr Comp Physiol 2013;304:R523-R530.

66. Jacka FN, Overland S, Stewart R, Tell GS, Bjelland I, Mykletun A. Association between magnesium intake and depression and anxiety in community-dwelling adults: The Hordaland Health Study. Aust N Z J Psychiatry 2009;43:45-52.

67. Nahm FS. What the P values really tell us. Korean J Pain 2017;30:241-242.

68. Briefel RR, Sempos CT, McDowell MA, Chien S, Alaimo K. Dietary methods research in the third National Health and Nutrition Examination Survey: Underreporting of energy intake. Am J Clin Nutr 1997;65 Suppl 4:S1203S1209.

69. Hennekens $\mathrm{CH}$, Buring JE. Epidemiology in medicine, 1st ed. Philadelphia, PA: Lippincott Williams and Wilkins, 1987:400.

70. Kosinski M, Matz SC, Gosling SD, Popov V, Stillwell D. Facebook as a research tool for the social sciences: Opportunities, challenges, ethical considerations, and practical guidelines. Am Psychol 2015;70:543-556.

71. Akbaraly TN, Brunner EJ, Ferrie JE, Marmot MG, Kivimaki M, Singh-Manoux A. Dietary pattern and depressive symptoms in middle age. $\mathrm{Br} J$ Psychiatry 2009;195:408-413.

Cite this article as: McCabe D, Bednarz J, Lockwood C, Barker TH (2020) Specific nutrient intake via diet and/or supplementation in relation to female stress: A cross-sectional study, Women's Health Report 1:1, 241-251, DOI: 10.1089/whr.2020.0035.

$\begin{aligned} & \quad \text { Abbreviations Used } \\ & \mathrm{Cl}=\text { confidence interval } \\ & \mathrm{DHA}=\text { Docosahexaenoic acid } \\ & \mathrm{DP}=\text { dietary pattern } \\ & \mathrm{DQES}=\text { Dietary Questionnaire for Epidemiological Studies } \\ & \mathrm{DS}=\text { Dietary Supplement } \\ & \mathrm{DSQ}=\text { Dietary Supplement Questionnaire } \\ & \mathrm{EPA}=\text { Eicosapentaenoic acid } \\ & \mathrm{FFQ}=\text { Food Frequency Questionnaire } \\ & \mathrm{MD}=\text { Mean Difference } \\ & \mathrm{MTHFR}=\text { methylenetetrahydrofolate reductase } \\ & \mathrm{MVM}=\text { multivitamin and mineral } \\ & \mathrm{NHANES}=\text { National Health and Nutrition Examination Survey } \\ & \mathrm{PSS}=\text { Perceived Stress Scale } \\ & \mathrm{PUFA}=\text { polyunsaturated fatty acid } \\ & \mathrm{SD}=\text { standard deviation } \\ & \mathrm{SFQ}=\text { Supplement Frequency Questionnaire } \\ & \mathrm{SUQ}=\text { Supplement Use Questionnaire } \\ & \mathrm{VITAL}=\text { Vitamins and Lifestyle }\end{aligned}$

